\title{
TRAJETÓRIAS E NARRATIVAS DE ADOLESCENTES ENVOLVIDOS COM A CRIMINALIDADE: OS OBJETOS E SUAS FORMAS DE APROXIMAÇÃO EM TRANSDISCIPLINARIDADE
}

TRAJECTORIES AND NARRATIVES FROM ADOLESCENTS INVOLVED IN CRIMINALITY: OBJECTS AND APPROACHING PROCEDURES IN TRANSDISCIPLINARITY TRAYECTORIAS Y NARRATIVAS DE ADOLESCENTES INVOLUCRADOS CON LA CRIMINALIDAD: LOS OBJETOS Y SUS FORMAS DE APROXIMACIÓN EN TRANSDISCIPLINARIEDAD

\author{
Rodrigo Goes e Lima* \\ Claudia Wermelinger ${ }^{* *}$ \\ Lucas Caetano Pereira de Oliveira ${ }^{* * *}$ \\ Bráulio Figueiredo Alves da Silva ${ }^{* * *}$
}

\begin{abstract}
RESUMO
Este trabalho tem por objetivo mapear alguns dos conceitos que servem de fundamentação teórica para a pesquisa Curso de vida e trajetória delinquencial: um estudo exploratório dos eventos e narrativas de jovens em situação de vulnerabilidade (IEAT/UFMG). Partimos de uma breve conceituação dos objetos da pesquisa, a saber, adolescências, violência e criminalidade, para então chegarmos às formas de apreensão escolhidas, tendo como referência os campos da psicanálise, a partir da noção de narrativas, e o da sociologia, a partir da trajetória. Por fim, realizamos uma breve consideração acerca do desafio epistemológico de se construir tais conceitos em uma abordagem transdisciplinar.
\end{abstract}

Palavras-chave: Adolescências. Violência. Criminalidade. Trajetória. Narrativa. Transdisciplinaridade.

\section{ABSTRACT}

This work aims to explore some of the concepts that establish the theoretical foundation for the research "Life course and criminal trajectory: an

\footnotetext{
*Pós-graduando em Psicanálise: Clínica da Criança e do Adolescente (PUC Minas), psicólogo pela Universidade Federal de Minas Gerais (UFMG), com ênfase em Processos Clínicos e Formação Complementar Aberta em Ciência Política, integrante do Núcleo Psilacs - Psicanálise e Laço Social no Contemporâneo. E-mail: rodrigo.goeselima@gmail.com.

** Mestra em Sociologia pela UFMG, graduada em Ciências Sociais pela UFMG, integrante do Núcleo Psilacs - Psicanálise e Laço Social no Contemporâneo e do Grupo de Pesquisa "Curso de vida e trajetória delinquencial”" do Instituto de Estudos Avançados Transdisciplinares da (IEAT/UFMG).E-mail: claudia.sws@gmail.com.

***Mestrando em Sociologia pelo Programa Programa de Pós-Graduação em Sociologia da UFMG, graduado em Ciências Sociais pela UFMG, bolsista CAPES, pesquisador do Centro de Estudos de Criminalidade e Segurança Pública (Crisp/UFMG). E-mail: kaetanolucas@gmail.com.

****Professor adjunto do departamento de Sociologia da UFMG, pesquisador do Centro de Estudos de Criminalidade e Segurança Pública e do Centro de Pesquisas Quantitativas em Ciências Sociais da UFMG. E-mail: braulio.fas@gmail.com.
} 
exploratory study of events and narratives of socially vulnerable adolescents" (IEAT/UFMG). We start from a short description of our research objects, namely, adolescence, violence and criminality so as to reach the chosen approaching methods (narrative and trajectory) having as reference the field of psychoanalysis, based on the idea of narratives and sociology, based on the idea of trajectory. At last, we state brief comments on the epistemological challenge of developing these concepts through a transdisciplinary perspective.

Keywords: Adolescences. Violence. Criminality. Trajectory. Narrative. Transdisciplinarity.

\section{RESUMEN}

Este trabajo tiene como objetivo mapear algunos de los conceptos que sirven de fundamentación teórica para la investigación "Curso de vida y trayectoria delincuencial: un estudio exploratorio de los eventos y narrativas de jóvenes en situación de vulnerabilidad" (IEAT/UFMG). Partimos de la breve conceptualización de los objetos de la investigación, a saber, adolescencias, violencia y criminalidad, para entonces llegar a las respectivas formas de aprehensión escogidas, teniendo como referencia los campos del psicoanálisis, a partir de la noción de narrativas, y el de la sociología a partir de la trayectoria. Por último, realizamos una breve consideración acerca del desafío epistemológico de construir tales conceptos en un enfoque transdisciplinario.

Palabras clave: Adolescencias. Violencia. Delito. Trayectoria. Narrativa. Transdisciplinariedad.

\section{INTRODUÇÃO}

Tendo como foco o complexo fenômeno da adolescência envolvida com a criminalidade, tópico que convida a uma reflexão sobre a violência, nós nos deparamos com o desafio metodológico de adotarmos vias de aproximação de nossos objetos em harmonia com as disciplinas e saberes dos quais nos dispusemos partir, em particular, a Psicanálise e a Sociologia, no âmbito da pesquisa "Curso de vida e trajetória delinquencial: um estudo exploratório dos eventos e narrativas de jovens em situação de vulnerabilidade" (Instituto de Pesquisa Econômica Aplicada [IEAT]/UFMG).

Por um lado, a psicanálise freudo-lacaniana nos fornece parâmetros que orientam a pesquisa de fenômenos sociais, considerando os atravessamentos singulares e inconscientes que perpassam as histórias de vida dos adolescentes, 
particularmente pelo uso das narrativas memorialísticas como dispositivo de apreensão de tais histórias (Guerra, Moreira, Oliveira, \& Lima, 2017). Já a Sociologia, notadamente pela contribuição de Elder Júnior. (1985), abre caminho para a compreensão de como eventos estruturais alteram as trajetórias dos sujeitos. A narrativa como métodos de aproximação ao sujeito adolescente faz emergir uma abordagem que permite estruturar suas trajetórias ao longo do seu curso de vida.

Assim, tomar diferentes pontos de partida teóricos mediante objetos complexos significa assumir, de antemão, uma posição interdisciplinar que, como veremos, convida, no decorrer das etapas de pesquisa, a desenvolvimentos multi e eventualmente transdisciplinares. Com base nesse propósito investigativo, apresentamos a seguir nossos objetos de pesquisa nas perspectivas teóricas da Psicanálise e da Sociologia, para então apontarmos as formas de aproximação escolhidas para estudá-los. Destacamos o potencial do diálogo entre as noções de narrativa e trajetória para capturar o caráter multidimensional da adolescência, de forma atenta à maneira como violência e criminalidade atravessam tal experiência.

\section{OS OBJETOS EM TRANSDISCIPLINARIDADE (ADOLESCÊNCIAS, VIOLÊNCIA E CRIMINALIDADE)}

\subsection{Adolescências}

A adolescência como fase de transformaçôes biológicas, psicológicas e sociais, que marcam a transição entre a infância e a idade adulta, é um produto das mudanças históricas advindas da Modernidade. A partir dos séculos XVI e XVII, ocorrem uma série de reformas e movimentos de moralização ligados às esferas religiosas, jurídicas e estatais que colocam a criança e a família nuclear em um lugar de maior importância na dinâmica social. As relaçôes familiares, gradativamente, passam a ser embasadas primordialmente pelo sentimento de afeição entre seus membros (Ariès, 1981). A progressiva expansão do ideal de universalização da educação pela escolaridade obrigatória, especialmente na Europa, também promoveu o processo de incorporação tardia das crianças ao status adulto, normalmente identificado pela participação no mercado de trabalho. ${ }^{5}$

\footnotetext{
Assim, a generalização da vivência cada vez mais tardia de experiências

5 Dayrell (2007) argumenta que a juventude brasileira, ao contrário da europeia, não pode ser caracterizada pela moratória em relação ao labor, uma vez que, historicamente, parte da juventude brasileira vivencia uma sobreposição entre os projetos de escolarização e trabalho. Por outro lado, Sposito, Sousa \& Arantes (2018) apontam que as transformaçôes econômicas e sociais ocorridas durante a primeira década dos anos 2000 resultaram na crescente tendência de acesso e permanência na escola pelas classes mais desfavorecidas.
} 
relacionadas ao mundo adulto teve como consequência a formação de um novo grupo, com hábitos, maneiras e problemas comumente partilhados: a adolescência. Nesse contexto, músicas, danças, estética, corpo, consumo e outras formas de expressão funcionam como uma base para o estabelecimento de identidades individuais e coletivas, gestadas pela convivência em grupos de pares e espaços de socialização múltiplos, heterogêneos e concorrentes que se orientam em direções tão diversas como a prática esportiva, a mobilização cidadã e eventualmente para açôes delinquentes e agressivas (Dayrell, 2007). Dessa forma, a multiplicidade de experiências e de atravessamentos estruturais (raça, gênero, classe e outros) produz vivências adolescentes diversificadas e exige que se compreenda a adolescência por sua historicidade e seu caráter dinâmico (Frota, 2007). Ao fazer isso, podemos perceber como os diferentes modos de ser adolescente expressam transformações nas formas como as sociedades ou coletivos produzem subjetividades/individualidades.

Apesar de não ser um termo propriamente psicanalítico, Freud $(1905 / 2016)^{6}$, com base na noção de puberdade, e, mais tarde, Lacan nos permitem pensar a adolescência como a "Enumeração de uma série de escolhas sintomáticas em relação a esse impossível encontrado na puberdade" (Stevens, 2004, p. 31). Em outras palavras, a partir das transformações púberes, o jovem se vê convocado a elaborar soluções para dar conta das novas exigências que lhe são apresentadas, diferentes daquelas até então recobertas pelo saber infantil. Para Freud (1905), a partir da constituição, durante a infância, de um "aparelho altamente complicado, que aguarda utilização" (p. 123), as transformações da puberdade permitem que o corpo receba e reaja a estímulos provenientes de três fontes: o mundo exterior, o interior orgânico e a vida psíquica (p. 123), implicando toda a mobilização de um intenso trabalho subjetivo. Duas dimensões se fazem importantes nessa concepção.

A primeira pode ser tratada com base na compreensão de Stevens (2004), de que a esse real da puberdade que modifica o corpo conviria chamar antes de "irrupção" do que de transformação, uma vez que há "uma emergência de alguma coisa sobre a qual as palavras falham [... ]. Trata-se menos de transformação do que de eclosão de alguma coisa radicalmente nova" (p. 33). Ainda segundo o autor, esse novo se trata do "reaparecimento, para o sujeito, de sua falha de saber no real" (p. 33). Somos aqui então remetidos ao segundo ponto. Se dizemos de um "reaparecimento" é pelo fato de levarmos em conta os dois tempos da sexualidade na teoria freudiana, sendo o primeiro o da infância e o segundo o da puberdade, momento em que, "quando tudo deveria contribuir para o encontro sexual, este não fosse senão mais traumatizante" (Cottet, 1996, p. 12).

6 A primeira data indica o ano de publicação original da obra, e a segunda, a edição consultada pelo autor, a qual somente será pontuada na primeira citação da obra no texto. Nas seguintes, será registrada apenas a data de publicação original. 
Tal constatação é imprescindível para a compreensão da concepção de adolescência à luz da psicanálise, uma vez que esta retira "a criança e o adolescente de uma abordagem evolucionista ou de estágios", introduzindo no lugar "um critério temporal, mas não desenvolvimentista" (Cottet, 1996, p. 8). Nessa vertente, ao dar ênfase ao "real do sexo" (p. 10), a psicanálise aponta uma lógica temporal que respeita, antes, a natureza estrutural do trauma. Faz-se então necessário uma estratégia metodológica de apreensão de uma complexidade subjetiva não submetida a etapas desenvolvimentistas que se procedem linearmente no tempo cronológico.

Assim, uma questão interessante do fenômeno da adolescência na Contemporaneidade habita na lacuna entre a maturidade biológica e a maturidade social. Se, por um lado, a puberdade acontece cada vez mais cedo (Monte, Longui \& Calliari, 2001), o prolongamento do processo de escolarização e o aumento da expectativa de vida possibilitam o adiamento cada vez maior da entrada na vida adulta. É possível que essa situação crie uma indefinição a respeito do papel social desses indivíduos no contexto contemporâneo, já que é cada vez mais difícil definir modelos de transição num quadro em que as trajetórias se tornam progressivamente mais individualizadas.

A complexidade desse cenário coloca desafios à apreensão dos processos sociais e psíquicos envolvidos nessa etapa de vida. Veremos adiante que a análise das trajetórias e das narrativas proporciona um acesso privilegiado aos processos subjetivos desses indivíduos bem como ilustram o duplo vínculo entre as instâncias individuais e sociais. É a partir da experiência narrada que podemos acessar, simultaneamente, a força das estruturas e as possibilidades de agência individual.

\subsection{Violência}

A consideração da dimensão psíquica em psicanálise nos remete ao estabelecimento da distinção entre "violência", "agressividade" e "ato agressivo" com base na obra lacaniana, como explicam Guerra, Cunha, Aranha, Souza, Penna e Silva (2015). No que diz respeito à violência propriamente dita, entenderíamos a presença de uma conexão estreita com o que Freud (1920/1980) chamou de pulsão de morte, que nomeia aquilo que "não faz vínculo com o mundo através da linguagem, ao que excede o corpo e a capacidade de representação do aparelho psíquico" (Guerra et al., 2015, p. 43). Associa-se então a violência à face desagregadora da dimensão pulsional, que não recebe tratamento simbólico, e que convoca a uma repetição, por meio da qual o aparelho psíquico "visa a encontrar uma tradução, uma vinculação para o excesso" (Guerra, Soares, 
Pinheiro, \& Lima, 2012, p. 253).

Lembramos que, no processo de constituição do sujeito, o bebê assume uma imagem antecipada de si mesmo com base na imagem especular do outro, ao que Lacan (1950) atribui o nome de "estádio do espelho". Pela agressividade, o sujeito articula o movimento de "diferenciação em relação ao outro" (Guerra et al., 2015, p. 44), fazendo dela um componente estrutural e constitutivamente subjetivo. No que diz respeito ao "ato agressivo", estaríamos diante então da presentificação dessa dimensão estrutural da agressividade, uma "exacerbação da agressividade estrutural que compóe a relação original do sujeito falante na relação com a alteridade" (p. 44), e que pode vir a se constituir como via de resposta do sujeito no que diz respeito a sua relação com os desafios diante dos quais a puberdade o coloca (Guerra \& Pinheiro, 2011).

Nas Ciências Humanas, a violência é um tema sobre o qual temos um tênue consenso que, segundo Castro (2002), é ditado mais pelo senso comum (que classifica qualquer agressão física intencional como violência) do que por definições conceituais compartilhadas pelas diferentes correntes teóricas.

Collins (2008), numa abordagem microssociológica, sugere que a violência não seja uma característica dos indivíduos, mas das situações. Dessa forma, o que deve ser compreendido é o processo pelo qual as interações, normalmente pacíficas, transformam-se em eventos violentos. Nessa perspectiva, a violência é resultado da dinâmica das emoções, particularmente o medo, a raiva e a excitação, que, em situações específicas de confronto, levam à agressão. Tal abordagem se coloca como tese complementar às demais explicações da violência.

A Organização Mundial da Saúde (OMS) tem uma definição ampla do fenômeno. Considera-se violência como o uso de força física ou poder, pela ameaça ou pela prática, contra si mesmo ou contra terceiros (sejam indivíduos, grupos ou comunidades), que resulte ou possa resultar em sofrimento, morte, dano psicológico, desenvolvimento prejudicado ou privação (Dahlberg \& Krug, 2006). Tal definição cobre uma ampla gama de resultados, que não incluem necessariamente sofrimento e morte e que, mesmo assim, têm enorme peso na vida de indivíduos, famílias e comunidades (Dahlberg \& Krug, 2006).

$\mathrm{Na}$ mesma linha de raciocínio, Michaud (1989) considera a violência como um tipo de relação social e acredita que, para a apreensão desse fenômeno, devemos operar com uma conceituação ainda mais ampla em que também se considerem os aspectos subjetivos, como motivações, sentimentos e sensações de autores e vítimas (Abromovay, 2006). A ampliação do escopo da definição do conceito também demonstra seu caráter histórico e reflexivo. Por um lado, ela responde ao processo histórico de mudança na sensibilidade dos indivíduos 
(Elias, 1994), que permite o reconhecimento de modalidades não físicas de confronto como eventos violentos.

Verificamos, assim, que tanto violência quanto agressividade se inserem, de uma forma ou de outra, nas referências de uma ideia de civilização, na relação com o outro e nas fronteiras da linguagem (Guerra, 2014). Mas, independentemente do conceito ou da abordagem adotados, o fato é que impressionam os números brasileiros ${ }^{7}$ que dizem respeito à violência, particularmente relativos à juventude. Segundo o Atlas da Violência (Instituto de Pesquisa Econômica Aplicada [IPEA], 2018), somente em 2016, foram 33.590 jovens de 15 a 29 anos assassinados, sendo que os homicídios representavam $56,5 \%$ da causa da morte de homens de 15 a 19 anos (IPEA, 2018). Desse modo, podemos afirmar que a experiência com algum tipo de violência perpassa o curso de vida de uma parcela considerável dos jovens no Brasil, considerando sempre que "não há discussão que envolva a violência que se faça sem a consideração da dimensão política de fundo que fornece seu enquadre" (Guerra, 2014, p. 27).

Diante deste esse cenário, perguntamos: se a violência pode se apresentar como forma de resposta ao não simbolizável da puberdade, podemos localizar na narrativa um recurso que transporta o jovem de volta à linguagem na condição de sujeito respondente? E, considerando o desenvolvimento de um percurso de vida transpassado por situações violentas, pode a reconstrução das trajetórias pelas narrativas contribuir para o entendimento da emergência da violência em certos contextos sociais? Tendo em consideração tais questóes, passemos ao conceito de criminalidade.

\subsection{Criminalidade}

Dizer que o crime é um fato social significa dizer que se trata de um fenômeno presente em todas as sociedades, que existe independentemente da vontade individual e exerce alguma coerção sobre os indivíduos (Durkheim, 1985). Além disso, para Durkheim (1985), o crime é um fenômeno funcional e útil. A sua funcionalidade se encontra na punição, pois o crime é um ato que ofende o conjunto da sociedade de tal modo esta precisa ser restituída. Assim, a punição é o instrumento dessa restituição moral, funcionando como reforço dos sentimentos coletivos em torno das normas sociais. Sua utilidade se apresenta, por outro lado, ao proporcionar à sociedade um momento de reflexão sobre a aceitabilidade ou não de um ato, promovendo a inovação social pela modificação

\footnotetext{
7 É preciso ter em mente o quadro geral no qual se insere a violenta realidade brasileira. Tomando os homicídios como um índice de violência, segundo as informações compiladas pelo Atlas da violência (IPEA, 2018), as Américas, e particularmente a América do Sul, apresentam as mais altas taxas de homicídio do mundo. Enquanto, em 2012, a Europa e a Oceania apresentaram uma taxa de menos de 2 homicídios para cada 100 mil habitantes, as Américas apresentam uma taxa de cerca de 14 homicídios para cada 100 mil habitantes.
} 
das normas. É pela punição que conhecemos o crime e pelas mudanças daquilo que merece punição, e nas formas de punir, que podemos vislumbrar uma face do caráter dinâmico das sociedades.

Historicamente, a reforma das instituições penais no início da Era Moderna significou, entre outras coisas, a emergência da distinção entre a falta moral e infração penal. A lei deve então dizer o que é o crime e qual a pena associada a ele, garantindo um tratamento igualitário e justo para os cidadãos (Lanier $\&$ Henry, 2001). No entanto é preciso pontuar que o crime não é produzido apenas pela legislação. É importante considerar simultaneamente o papel daqueles que são encarregados da criação e aplicação das leis e daqueles que administram as penas na construção do fenômeno da criminalidade. As agências do Sistema de Justiça Criminal tendem a atuar de maneira seletiva e a perseguir os crimes praticados por estratos populacionais tidos como "problemáticos" ou "vulneráveis", tornando a noção de criminalidade um dispositivo de gestão da pobreza e das populações marginalizadas (Paula, 2014; Wacquant, 1999).

Para se ter uma ideia, o Brasil tem a terceira maior população prisional do mundo, com mais de 720 mil presos (Fórum Brasileiro de Segurança Pública [FBSP], 2018). Assim como os adolescentes em poder do sistema socioeducativo, a maior parte daquela população é composta por jovens do sexo masculino, pretos e pardos, pobres, de baixa escolaridade e que recebeu sanção judicial por conta da posse de pequenas quantidades de drogas ou pequenos crimes contra $o$ patrimônio (FBSP, 2018).

Em Introdução teórica às funções da psicanálise em criminologia, Lacan (1950) aponta, logo de saída, que "Nem o crime nem o criminoso são objetos que se possam conceber fora de sua referência sociológica" (p. 128). Tal advertência não impede, no entanto, que a psicanálise apresente um modo particular de pensar a criminalidade que, segundo Salum (2009), pode ser distinguida com base em duas perspectivas. A primeira delas se sustenta sobre a posição psicanalítica de não desumanizar o criminoso, ao tomá-lo como sujeito capaz de responder pelo seu ato, que, por sua vez, é imbuído de natureza simbólica. Haveria espaço, assim, para uma contribuição da psicanálise à criminologia na vertente da operação analítica. Em segundo lugar, de acordo com a autora, estaria a contribuição que o campo criminológico apresentaria à psicanálise ao "fazer avançar a teoria e a prática analítica além da referência edipiana” (p. 129). Uma derivação importante dessa relação aparece, por exemplo, nos desenvolvimentos a respeito da noção de responsabilidade e assentimento, cruciais para a teoria psicanalítica lacaniana. Nas palavras de Salum (2009), 
$\mathrm{O}$ assentimento está articulado aos modos de resposta. Esse conceito revela a problemática do sujeito às voltas com a lei. Certamente, a lei que interessa à psicanálise não é a mesma que importa ao direito. Ela não é a norma. A lei jurídica se orienta pelo ideal, tem como objetivo a normatização das condutas. A lei que interessa à psicanálise é aquela que visa o singular, que institui a particularidade (p. 130).

Tais formulações são importantes quando consideramos como a experiência da criminalidade pode atravessar o sujeito adolescente. Guerra et al. (2012) hipotetizam, por exemplo, que, diante da queda das soluçôes infantis para dar conta dos novos enigmas postos pela puberdade, o jovem adere ao saber rígido ofertado pelo crime para se inscrever no laço social. Temos, portanto, anexado à noção de criminalidade, não apenas uma vertente eminentemente sociológica, mas também um aspecto subjetivo importante, uma vez que o crime parece apresentar uma solução singular ao jovem que se vê interpelado pela puberdade e que encontra na atividade ilícita uma saída para o impasse adolescente. Nesse ponto a convoca o sujeito a uma resposta mediante seu ato. Retomando Salum (2009), lembramos que

O crime é um ato cujas consequências ultrapassam o sujeito, pois ele atinge o Outro. Por isso, seu estatuto é o de ser um fato social. Devido a essa característica, ele convoca respostas sociais que visam responder ao mal que ele provoca. Lacan é partidário dessa concepção, ao precisar que a responsabilidade é o que a psicanálise visa no trabalho com o infrator (p. 57).

No que tange a nosso objeto de pesquisa (o adolescente em conflito com a lei) a abordagem com base na Sociologia e na Psicanálise tenta englobar aspectos objetivos e subjetivos que unem os fenômenos abordados até aqui: a adolescência, a violência e o crime. Diante da complexidade de nossos objetos, buscamos apreender os aspectos legais, sociais e recortes demográficos e subjetivos do atravessamento da criminalidade na passagem adolescente.

Entendemos que diagnósticos psicológicos ou sociológicos, tomados isoladamente, não são capazes de elucidar por completo a passagem entre as estruturas sociais e a ação individual e, especificamente, na experiência de cada indivíduo, a passagem ao ato infracional ou a desistência do crime. Considerando as estatísticas apresentadas e as particularidades destacadas relativas aos conceitos trabalhados, procedemos ao detalhamento de nossas formas de aproximação desses objetos, para pensar como a experiência transdisciplinar se insere nesse contexto investigativo. 


\section{AS FORMAS DE APROXIMAÇÃO DO OBJETO EM TRANSDISCIPLINARIDADE}

\subsection{Curso de vida e trajetórias}

A perspectiva do "curso de vida" procura compreender o impacto de eventos estruturais na vida das pessoas e como esses eventos influenciam as "coortes" e modelam o caminho percorrido pelos indivíduos ao longo de suas vidas. Nesse registro, a noção de temporalidade assume três sentidos (Elder Júnior \& Rockwell, 1979). A “idade cronológica”, isto é, o tempo existente entre nosso nascimento e morte, período no qual os indivíduos se desenvolvem biológica, psicológica e socialmente (Elder Júnior (1985). A "idade histórica”, obtida pelo ano de nascimento, marca o pertencimento a uma coorte específica e se relaciona com a história e as mudanças sociais. Os indivíduos são expostos, portanto, a um pedaço da experiência histórica no processo de atravessamento dos papéis estruturados conforme a idade e compartilham muito dessa experiência de vida com outros membros de sua coorte. Por fim, a "idade social" identifica padrões etários nos papéis sociais e calendários culturais. Cada cultura em cada época específica define expectativas e normas para cada faixa etária.

Entendemos "trajetória" como um caminho ao longo da vida ou uma carreira que pode variar e mudar de direção, grau e proporção, abarcando várias dimensões interdependentes como o trabalho, escolaridade e envolvimento com o crime. As "transiçõos" se referem a mudanças de estado, posição ou situação, não necessariamente predeterminados ou absolutamente previsíveis, e que podem ocorrer simultaneamente (entrar no mercado de trabalho, casar, ter filhos), sendo descritas segundo seu timing, sequência e duração (Blanco, 2011). Nesse sentido, as sociedades urbanas contemporâneas também estabelecem "normas" e "expectativas" baseadas na idade que marcam "transiçôes" e dividem nossas vidas em diferentes "trajetórias".

Para Elder Júnior (1985), a dinâmica do curso de vida se dá pela relação de interdependência entre as trajetórias e as transições, sendo possível observar padrões, apesar das particularidades de cada história individual. As transições mais evidentes são aquelas marcadas por "eventos" que estão inseridos dentro das trajetórias no curso de vida de cada indivíduo.

"Eventos" são ações ou acontecimentos situados na vida dos indivíduos que, apesar de serem gerais para todos os grupos sociais ou coortes, são particulares/ significativos em suas consequências para os sujeitos. Nesse sentido, eventos ocorrem dentro das trajetórias e, dependendo de sua natureza e duração, e os recursos, motivações, crenças e definições que o agente traz para a situação, 
podem tanto reforçar padrões emergentes de trajetórias como alterar ou redirecionar uma trajetória processual. Quando os eventos desencadeiam uma descontinuidade em transições, trajetórias ou no curso de vida como um todo, são denominados turning-points.

Esse enfoque teórico busca conciliar abordagens de níveis micro e macroestruturais ao explorar simultaneamente as dimensões ligadas a "agência humana", "idade dos indivíduos", "vidas ligadas" a eles e o "lugar e tempo histórico" no qual estes se inserem. Nessa perspectiva, enfocamos a fase de transição que constitui a adolescência e buscamos compreender como os eventos ocorridos durante esse período marcam e alteram as trajetórias e a vida de parcela da juventude brasileira, particularmente no que diz respeito aos fatores ligados à entrada, permanência ou desistência da trajetória infracional.

\subsection{Narrativas}

Vimos acima que o conceito de trajetória possibilita um mapeamento cronológico da incidência de eventos diversos nos cursos de vida de nossos jovens. De forma auxiliar, a narrativa permite que o adolescente discorra sobre sua história de vida, abrindo vias para uma "instância interpretativa" (Bolívar, 2002, p. 4) que considere uma abertura subjetiva, amparada pela experiência de linguagem, e que conceda a possibilidade de um posicionamento do respondente como sujeito no discurso. A oportunidade de relatar livremente sua história possibilita ao sujeito que fala a elaboração de uma ficção que comporta a verdade dos fatos, com base na localização de pontos de fixação (ou de impossibilidade de se narrar) atravessados pela dimensão inconsciente do narrador e por uma série de versões da história que se conjugam no discurso sem se eliminarem. A narrativa dispõe, portanto, de um corpo e de um fundo político, a partir do qual a dimensão do outro que a escuta é sempre considerada sob um fundo transferencial (Guerra et al., 2017). Dessa maneira, exploramos aquilo que se rememora e como se diz aquilo que se lembra, fazendo com que se construa, com nossos sujeitos, um conhecimento sobre eles e sobre sua percepção sobre si, sobre seus outros significantes e sobre a sociedade de forma mais ampla, respeitando a cadeia associativa que orienta a construção narrativa.

A narrativa apresenta, portanto, saberes biográficos que concatenam eventos e suas consequências objetivas e subjetivas. A partir dela, podemos depreender a dinâmica de atualização das estruturas sociais e suas representações, que nunca ocorrem fora de um contexto. Para além do aspecto ficcional, encontrase ainda o caráter retrospectivo da narrativa, que, ao colocar o sujeito da experiência como portador de saber privilegiado dos acontecimentos, permite 
observarmos a emergência de pontos de concentração de sentido, carregados de relevância subjetiva e que podem, também, constituir turning-points. Indo além da cronologia da trajetória, a narrativa joga luz, por assim dizer, em pontos focais de sentido para o sujeito, que atuam como condicionantes de suas açôes e que constituem pontos chave para a compreensão dos nexos entre o social e o individual, indicando sua pertinência como elemento para uma abordagem transdisciplinar.

\section{PARA CONCLUIR: A TRANSDISCIPLINARIDADE EM ATO}

Ao empreendermos o esforço de explicitar brevemente os aspectos principais que concernem nossos objetos de pesquisa, assim como as respectivas formas de aproximação que adotamos para apreendê-los, buscamos formalizar os fundamentos teóricos de uma pesquisa que assume o desafio de uma construção transdisciplinar. Nesse sentido, partimos de uma construção interdisciplinar, por meio de discussões coletivas de elaboração conceitual e metodológica e que revelaram todo o potencial do processo conjunto de discussão e interpretação (Kazmierska, 2014). Em seguida, avançamos para uma fase multidisciplinar, ao concatenar, na prática de pesquisa em campo, os instrumentos (narrativas e questionários) aplicados por equipes de formações mistas, e de natureza "essencialmente aditiva" (Domingues, 2012, p. 15), cujos conhecimentos se justapunham. Como, enfim, dar o salto para o exercício trans, a partir dessa experiência?

É a partir das limitaçôes de nossas disciplinas que buscamos responder à pergunta. No encontro entre elas, verificamos uma tensão estrutural que, mediante a insistência no diálogo, conduziu a uma reformulação teórica e de perspectiva dos pesquisadores. Observamos então a emergência de uma nova postura investigativa transdisciplinar $\mathrm{em}$ ato, uma vez que esta se materializou no exercício da prática dialógica entre pesquisadores (e, eventualmente, entre os sujeitos de pesquisa), e em permanente negociação construtiva (Clifford, 1998).

A análise das trajetórias em conjunção com as narrativas possibilitou a contextualização biográfica da dinâmica complexa de atualização de modos de agir e pensar, tendo como pano de fundo a sequência de eventos interpretados e concatenados pelos sujeitos. A proposta linear e cronológica da trajetória busca dar uma ordenação a eventos significativos de uma vida, enquanto a proposta narrativa, baseada na lógica do a posteriori, permite não apenas que se compreenda uma outra natureza de arranjo de vivências e pontos de significação como também a possibilidade de inserção do saber do sujeito no fazer investigativo. Ao nos perguntarmos sobre o potencial das narrativas no 
âmbito do desenvolvimento de uma metodologia transdisciplinar, verificamos que tal inclusão é passo importante na construção dessa abordagem, uma vez que, como afirma Nicolescu (1999), "entre as duas extremidades do bastão simplicidade e complexidade - falta o terceiro incluído, o próprio indivíduo" (p. 19). Advém daí, então, um intenso e permanente desafio de ultrapassagem dos limites de cada disciplina a partir da consideração do saber do sujeito. Assim, acreditamos dar um primeiro passo contra o que seria uma "verdadeira lógica de exclusão" (p. 15), a partir do convite ao ato de palavra pelo qual o sujeito da narrativa pode alicerçar sua inserção na construção do saber. 


\section{REFERÊNCIAS}

Abromovay, M. (Coord.). (2006). Cotidiano das escolas: entre violências. Brasília: UNESCO.

Ariès, P. (1981). História social da criança e da família. Rio de Janeiro: LCT.

Blanco, M. M. (2011). El enfoque del curso de vida: orígenes y desarrollo. Revista Latinoamericana de Población, 5(8), 5-31.

Bolívar, A. (2002). “¿De nobis ipsis silemus?”: epistemología de la investigación biográfico-narrativa en educación. Revista Electrónica de Investigación Educativa, $4(1), 1-26$.

Castro, M. (2002). Violências, juventudes e educação: notas sobre o estado do conhecimento. Revista Brasileira de Estudos de População, 19(1), 5-28.

Clifford, J. (1998). Sobre autoridade etnográfica: a experiência etnográficaAntropologia e literatura no século XX. Rio de Janeiro: UFRJ.

Collins, R. (2008). Violence: a micro-sociological theory. Princeton: Princeton University Press.

Cottet, S. (1996). Estrutura e romance familiar na adolescência. In H. C. Ribeiro \& V. Pollo (Orgs.). Adolescência: o despertar. (pp. 7-20). Rio de Janeiro: Contra Capa.

Dahlberg, L. L. \& Krug, E. G. (2006). Violência: um problema global de saúde pública. Ciência \& Saúde Coletiva, 11(Supl.), 1163-1178.

Dayrell, J. (2007). A escola "faz" as juventudes? Reflexôes em torno da socialização juvenil. Educação e sociedade, 28(100), 1105-1128.

Domingues, I. (2012). Multi, inter e transdisciplinaridade: onde estamos e para onde vamos? Pesquisa em Educação Ambiental, 7(2), 11-26.

Durkheim, E. (1985). As regras do método sociológico. São Paulo: Martins Fontes, 2014.

Elder Júnior, G. H. (1985). Perspectives on life course. Ithaca: Cornell University Press.

Elder Júnior, G. H. \& Rockwell, R. C. (1979). The life-course and human development: an ecological perspective. International Journal of behavioral 


\section{Development, 2(1), 1-21.}

Elias, N. (1994). O processo civilizador. Rio de Janeiro: Jorge Zahar.

Fórum Brasileiro de Segurança Pública. (2018). 12ªnuário Brasileiro de Segurança Pública. São Paulo: Fórum Brasileiro de Segurança Pública. Recuperado a partir de http://www.forumseguranca.org.br/wp-content/uploads/2019/03/ Anuario-Brasileiro-de-Seguran\%C3\%A7a-P\%C3\%BAblica-2018.pdf

Freud, S. (1905). Três ensaios sobre a teoria da sexualidade. In P. C. Souza (Trad.), Obras completas. (Vol. 6, pp. 13-172). São Paulo: Companhia das Letras, 2016. (Publicado originalmente em 1905).

Freud, S. (1920). Além do Princípio do Prazer. In J. Salomão, J. Strachey (Ed.), Edição standard brasileira das obras psicológicas completas de Sigmund Freud. (Vol. 18, pp. 17-90). Rio de Janeiro: Imago, 1980. (Trabalho original publicado em 1920).

Frota, A. M. M. C. (2007). Diferentes concepções da infância e adolescência: a importância da historicidade para sua construção. Estudos e Pesquisas em Psicologia, 7(1), 144-157.

Guerra, A. M. C. (2014). Pelo enquadre ético da violência: psicanálise e política. In A. M. C. Guerra, A. T. Ferrari, \& M. S. Otoni (Ed.), Direito e psicanálise: controvérsias contemporâneas. (pp. 25-34). Curitiba: Editora CRV.

Guerra, A. M. C., Cunha, C. F., Aranha, M. C., Souza, M. B., Penna, P. D. M., \& Silva, R. S. (2015). A assistência social pública na interface entre subjetividade e política. Belo Horizonte: Scriptum.

Guerra, A. M. C., Moreira, J. O., Oliveira, L. V., \& Lima, R. G. (2017). The narrative memoir as a psychoanalytical strategy for the research of social phenomena. Psychology, 8(8), 1238-1253.

Guerra, A. M. C. \& Pinheiro, M. C. M. (2011). A escrita da violência na adolescência. In Anais, 6 Congresso Nacional de Psicanálise da Universidade Federal do Ceará. Fortaleza: UFC.

Guerra, A. M. C., Soares, C. A. N., Pinheiro, M. C. M., \& Lima, N. L. (2012). Violência urbana, criminalidade e tráfico de drogas: uma discussão psicanalítica acerca da adolescência. Psicologia em Revista, 18(2), 247-263.

Instituto de Pesquisa Econômica Aplicada (2018). Atlas da violência. Brasília: 
IPEA. Recuperado a partir de http://www.ipea.gov.br/portal/images/stories/ PDFs/relatorio_institucional/180604_atlas_da_violencia_2018.pdf

Lacan, J. (1950). Introdução teórica às funções da psicanálise em criminologia. In V. Ribeiro (Trad.), Escritos. Rio de Janeiro: Jorge Zahar, 1998. (Obra original publicada em 1950).

Lanier, M. M. \& Henry, S. (2001). Crime in context: the scope of the problem. In what is crime? Controversies over the nature of crime and what to do about it. (pp. 1-15). Lanham: Rowman \& Littlefield Publishers.

Michaud, Y. (1989). A violência. São Paulo: Ática.

Monte, O., Longui, C. A., \& Calliari, L. E. P. (2001). Puberdade precoce: dilemas no diagnóstico e tratamento. Arquivos Brasileiros de Endocrinologia \& Metabologia, 45(4), 321-330.

Nicolescu, B. (1999). O manifesto da transdisciplinaridade. São Paulo: Triom. Recuperado a partir de http://www.ruipaz.pro.br/textos_pos/manifesto.pdf

Paula, L. (2014). Justiça juvenil. In R. S. Lima, J. L. Ratton, \& R. G. Azevedo (Org.), Crime, polícia e justiça no Brasil. São Paulo: Contexto.

Salum, M. J. G. (2009). A psicanálise e o crime: causa e responsabilidade nos atos criminosos, agressôes e violência na clínica psicanalítica contemporânea. (Tese de Doutorado). Universidade Federal do Rio de Janeiro, Programa de PósGraduação em Teoria Psicanalítica, Rio de Janeiro.

Sposito, M. P., Souza, R., \& Arantes, F. (2018). A pesquisa sobre jovens no Brasil: traçando novos desafios a partir de dados quantitativos. Educação e Pesquisa, 44, 1-24.

Stevens, A. (2004). Adolescência, sintoma da puberdade: clínica do contemporâneo. Revista Curinga, Escola Brasileira de Psicanálise - Seção Minas, 20, 27-39.

Wacquant, L. (1999). As prisóes da miséria. Rio de Janeiro: J. Zahar. 